\title{
A case of Multiple primary malignancies including Peritoneal Mesothelioma surviving over 11 years
}

\author{
Ebrahim Esmati ${ }^{1}$ and Saeed Rezaei ${ }^{2}$ \\ ${ }^{1}$ Tehran University of Medical Sciences \\ ${ }^{2}$ Affiliation not available
}

December 18, 2020

\begin{abstract}
We present a patient with 3 separate primary cancers over the course of 11 years: Follicular Lymphoma, Abdominal mesothelioma and Rectal Adenocarcinoma respectively Multiple primary malignancies are exceedingly rare but they may occur sequentially in a patient. Peritoneal mesothelioma known as a fatal malignancy may completely regress with chemotherapy.
\end{abstract}

\section{Hosted file}

manuscript3.pdf available at https://authorea.com/users/383573/articles/499455-a-case-ofmultiple-primary-malignancies-including-peritoneal-mesothelioma-surviving-over-11-years

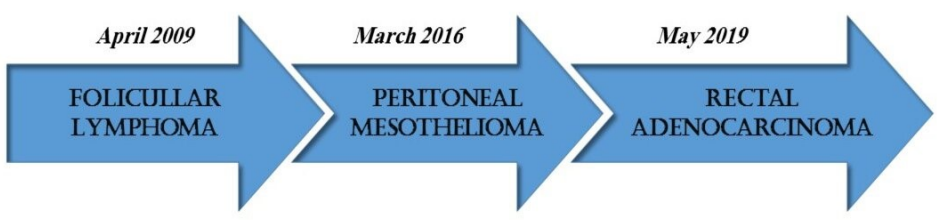




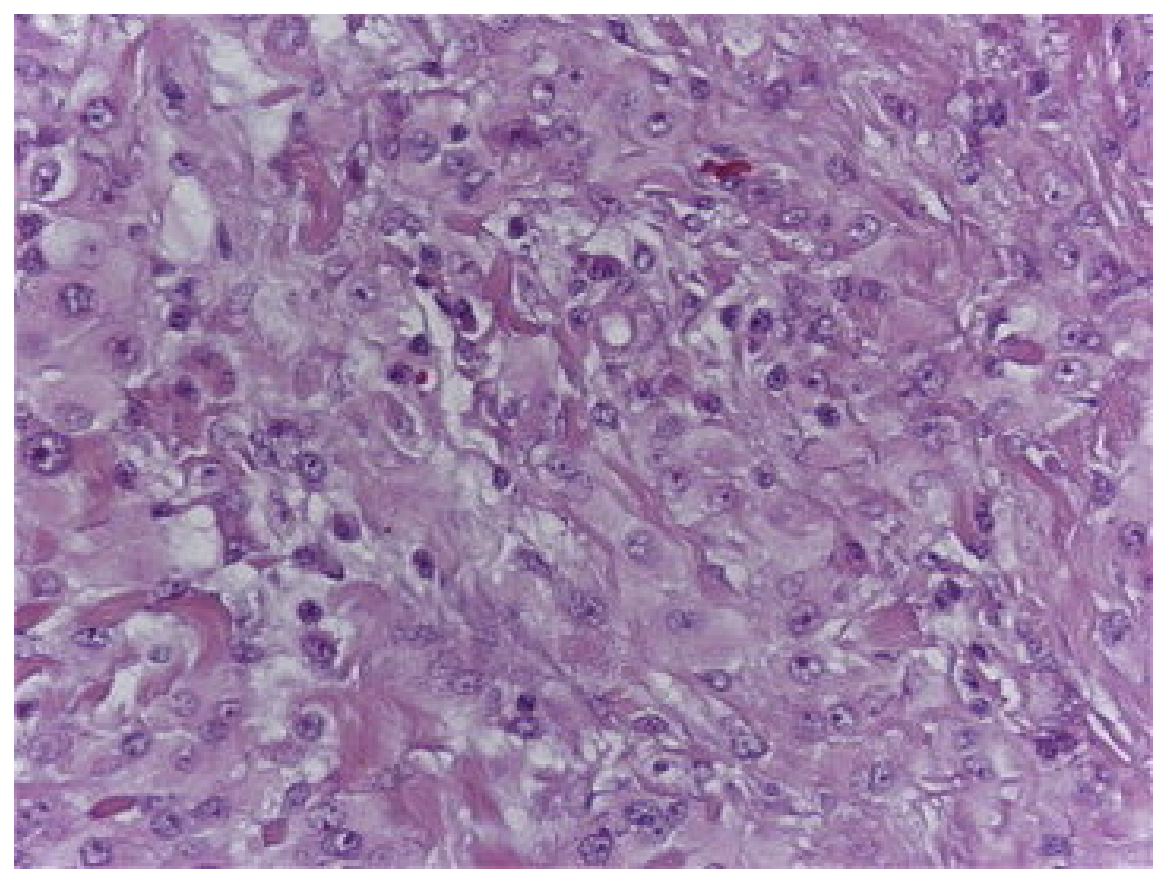

